EVIDENCE FOR EXPLICIT GLUEBALLS FROM THE REACTION $\boldsymbol{n}^{*} \mathrm{p}+\phi^{+}$

\title{
S.J. I.Indenbarm
}

Brookhaven Hational Leboratory, Upton, Hew York 11973

and

$\checkmark$ C1ty College of New York, New rork, New York 10031

NOTICE

Lecture presented at the 20th Course: Gauge Interaction: Theory and Experiment International School of Subnuclear Phyedce Erice, Trapani, Itely August 3-14, 1982
PORTIONS OF THIS REFORT ARE ILLEGIBLE. It has been reproduced from the best available copy to permit the broadest possible availahility.

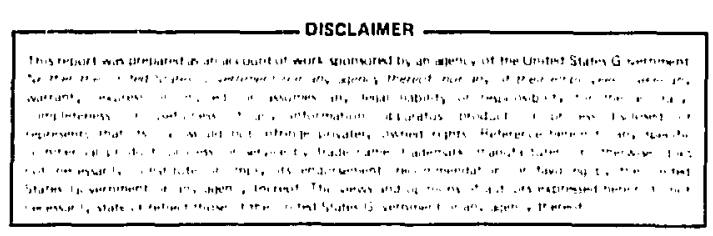

t Thie research was supp rted by the U.S. Departwent of Energy under

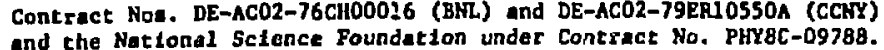

\section{MASTER}


EUIDENCE FOR EXPLICIT GLUEBALLS FROH THE REACTION $n-p \rightarrow \phi \$$

\section{s.J. Lindenbaum}

Brookhaven National Laboratory, Upton, New York 11973

and City College of New York, New York, New York 10031

\section{IATRODUCTION}

In a pure Yang-Mills theory ${ }^{1}$ where SU(3), has local gauge aymetry, all hadrons would be glueballs ${ }^{2}$ (1.e., multi-gluon resonances). Th1s is due to the self-coupling of the gluons which becomes atronger with decreasing energy and color confinement."

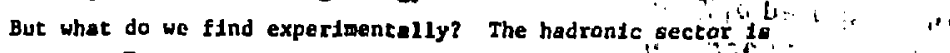
dominated by $q \bar{q}$ and $q 9 q$ and there is yet no prior "experilaental" demonatration of the explicit exiatence of glueballa, dichobgh":i there were a number of glueball candidates and extensive discuestion of them. ${ }^{3-17}$ Thus the quarks which are a source ${ }^{\star}$ of particlesiffor . . . gluons in QCD appear to have completely taken over the hadronic sector.

Therefore finding glueballa la crucial to QCD, Grand Unification Schemee and Partial Unification Schemes which utilize SU(3) In fact it has been the author's opinion for some $t 1 m e^{5,6}$ that if we don't stablish glueballa, QCD is In serious trouble. On the other hand, the explicit establishment of glueball's would Indeed be e greati triumph for QCD.

* Gluons are aleo a source of gluons due to the gelf-couplings in - non-Abelian Gruge Theory.
HOW DO YOU FIHD GLUEBALLS?

It 1a obvious from prior experimental observation that 1 glueballs exist they are essentlally ansked In the vast collection of meson nonets, existing in the moss range where one would expect to find them ( $1-3 \mathrm{GeV}$ ).

Pattern Recognition of a Decuplet

The direcr. approach is a complicated pattern recognition problem. Ore must find a nonet with a glueball with the same quantum numbers near enough to the alnglets in the nonet to $\mathrm{mlx}$ with them. Thus one would have

$$
\text { nonet + gluaball }+ \text { decuplet }
$$

with characteristic mixing and splitting (and other special characteristica of glueballa). Calculations have shom that the Ideal mixing observed in a great deal of nonets would be affected In these decuplets, and pattern recognition would have to be uged. 16,17 A glueball cancidate of this type is the sLAC $\mathrm{J}^{\mathrm{PC}}=\mathrm{O}^{-+}$ $1(1440),{ }^{8-10,16}$ which could be the tenth member of a Bround state $0^{-+}$decuplet." Another glueball candidate of this type 18 the BNL/ $C C N Y J^{P C}=0^{++} 8_{8}(1240) .15$ This vould make a new $0^{\text {t+ }}$ multiplet with apparently the right characteristics: of course one must realize that there are many other posalble explatations for these otates."

\section{Look in an O2I Suppressed Channel with a Varlable Mass}

In an 0ZI suppressed channel with variable mass glueballs with the right quantum numbers should break down the ozI suppression in the mass reglons where th=y exist, and doninate the rcaction

channel. Thus the 021 suppression can act as a fllter for letting

* The SLAC 1(1440) is thought to be in a channel where glueball are enhanced alnce $1 t$ is found in $\mathrm{J} / \mathrm{H}$ radiative decay.

t* One could for example Inadvertently mlx states trom the basic nonet with those of a radial excitation. 
glueballu pans while suppiessiog other gtates. Furthermore, the breakulown of the DZI suppression can serve as a clear signal that one or more glueballa are present in the mass region. The basic Idea 18 that according to present concepts in QCD, the OZI suppression 18 due to the fact thac two or more hard gluona are needed to bridge the gap in an ozl disconr ected or hatrpin diegram," and the early onset of asymptotic freedon leads to a relatively wesk coupling constant for these gluons, which then causes the ozI suppreasion. On the athar hand, if the glue in the interwediate atate renonateg to form a glueball, the effective coupling constant (as In all resonance phenosena) must become strong, and the 021 auppression abould disappear in the anas range of the glueball. This should allow hadronic atates with the glueball quantum numbers to form with easenstally no 02I suppresaion. This argument han been made previously by the author at ERICE ${ }^{5}$ and elsewhere. 6,13-14 Thus the 02I suppression easentislly acta as a filter which lets glueballs pass and suppresses quar'k statea.

THE $-p+q \rho$ (OZI FORBIDDEh CHANMEL)

The BNh/CCNY collaboration had shown several years ago that in the ozI forbidden ${ }^{18}$ (or suppi:esend) reaction I $^{-p}+$ pon at an incident plon energy of $22.6 \mathrm{GeV}$, that the $02 \mathrm{I}$ suppression was essentially abrent ${ }^{4}$ in th1s 021 forbidden process, This was quantitac1vely demonatrated, and interpreted by the author a evidence for gluetalle in the syatem. 5,6 However, initially 100 , and later 170, evente were obtajned and this small number did not allow a viable convincing pertial wave analysis to explicitly identify the glueball candidaten quantum numbers, mass, wid:h, etc. The observed toses spectrum in other later loy gtatiotics measuremente were consistent whth our reaulte. 19

- Three gluons are needed if the halrpin 18 a vector, two are needed if the hatrpin to a scaler.
However, BNL/CCNY planned anew experiment to obtain > than an order of magnitude more date thich would hopefully allow significant partial wave analyeia. In order to accomplish thio the BNL. MPS (Hultiparticle Spectrometer) was being redesigned so that a new novel high speed drift chamber system replaced the spark chambera and thus allowed gathering data at an order of wägnitude fagter rate. 20

Thte spring we successfully comissioned the new HPS II and In a 2-3 week run obtained $1203 x^{-} p+$ th events even though the visible cross section is only 26 nanobarns.

A partisl wave analysis of this data which was just presented at the Parls Conference, ${ }^{21}$ yielda two explicit strong glucball candidates in the system with all quantum numbers, mass and width deternined. The experiment was done at an 1ncident - energy of $22 \mathrm{GeV}$.

Let us now look at the diagrama in Fig. 1 which represent the varfous channels atudied in the experinent.

The basic reaction abserved is given by the ozt allowed resection (Fig. 10) $x^{-} P+K^{+} K^{-} K^{+} X^{-} D$.

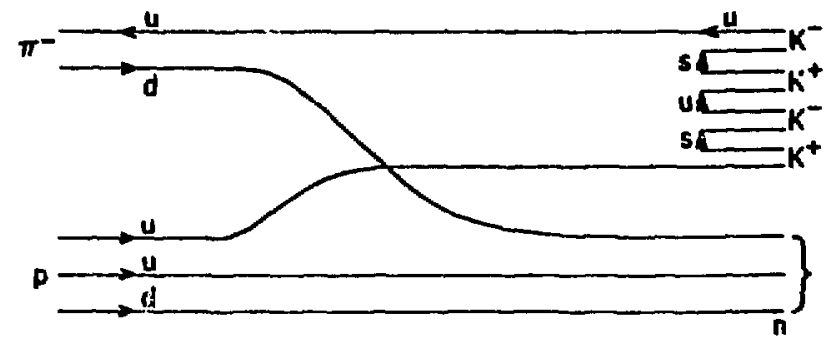

Figure la; The quark line diagram for the reaction $n-p \rightarrow K^{+} K^{-} K^{+} K^{-} n$, which is connected and $0_{\text {.in }}$ allowed. 
In QCD ${ }^{22}$ one considers these 021 ellowed reactions to proceed by * concinuous aerias of exchanges of angle and perhaps some low energy multiple gluong which have relatively atrong effective coupling conetante and thus proceed as atrong interactions. The poorly underatood hadronizacion procesu can to a large extent occur near the outer regions of the confinement region and have unsuppressed crose mections.

If one $k^{+} K^{-}$palr fora a we have the reaction $\pi^{-} p \rightarrow q K^{+} K^{-} \mathrm{n}$ (aee F1g. 1b) which 1o at111 a connected dlagram and 021 ellowed.

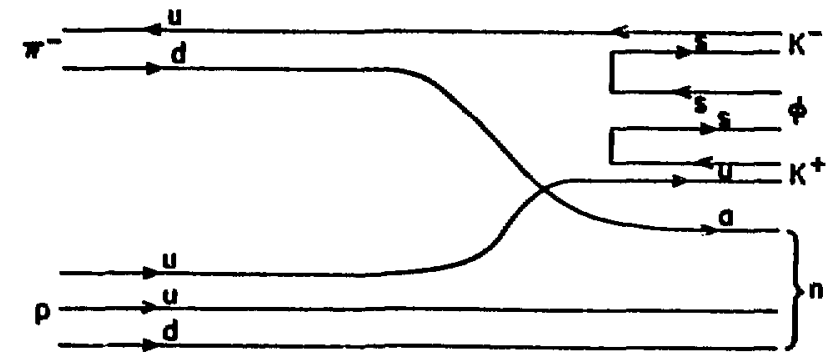

Figure lb: The quark line diagram for the ceaction $n^{-} \mathrm{P} \rightarrow \mathrm{K}^{+} \mathrm{K}^{-} \mathrm{n}$, which is connected and 021 allowed.

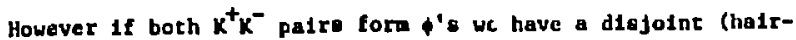
pin) diegraw which in 021 forbiddea. Thus $\bar{p} \rightarrow$ phe as shown in F1g. Ic is an 021 forbidden diagram and should exhibit the 021 ouppresicion.

Th1s has been clearly shown for $n \bar{p}+$ on where the ozI suppression factor has been found to be $w 100 .{ }^{23}$ Thus typlcally one Ilnde

$$
\frac{g\left(n^{-} p\right)+w n}{a\left(\pi^{-} p\right)+\phi n} \sim 100
$$

reflecting the ozI suppression factor.

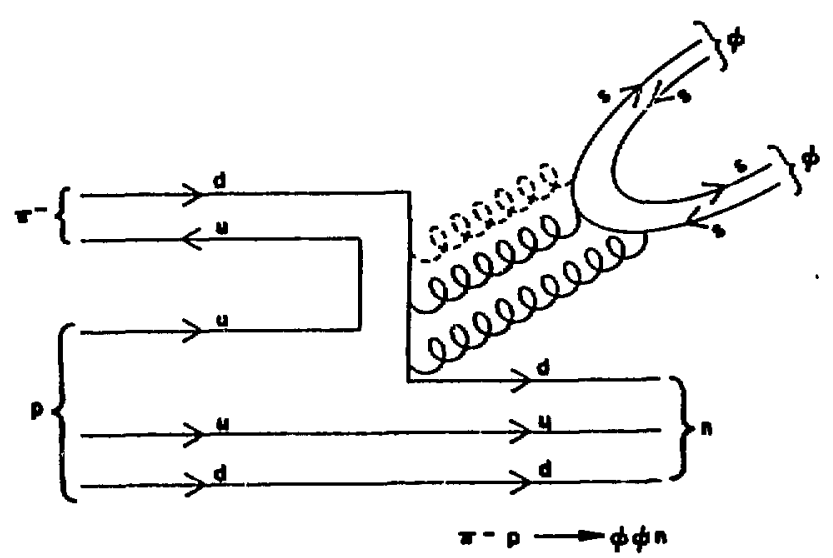

Figure 1c: The quirk line diagram for the reaction $n-p \rightarrow$ which 1a diajolnt (1.a. a halrpin dlagraw) and is ozI forbidden. Tuo or three Bluons ire shown connecting the disconnected parts of the diagram depending upon the quantur numbers of the ph system.

However, another OZI allowed process corresponding to a connected diagram is $K_{P}^{-}+\phi \Lambda$. The ratio

$$
\frac{O\left(K^{-} p\right)+1}{\sigma\left(x^{-} p\right)+p a} \neq 60
$$

again showing the typtcal OZI suppression. ${ }^{24}$

The decay matrix element squared of $+K^{+} K^{-}$(shoun in Fig. 2a), an 021 allowed process, is 2100 times that for $+p^{+}{ }^{-}$which 18 021 suppressed. ${ }^{18 a}$ llence in both the production and decay, a single halrpin (disfoint dlagram, eee gig. 2b), corresponds to an OZI suppresaion factor $\sim 100$.

Now you may ask is is as legitimate to consider $n-p \rightarrow q n$ also as a disfoint diagram subject to the OzL suppression. The angwer is clearly yes as I shall now demonstrate. Each of the two $\phi$ 's 


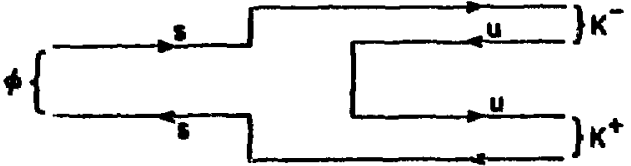

Figure 2a: The quark line diogram for the reaction $+K^{+} K^{-}$wh1ch Ia connected and thus 021 alloved.

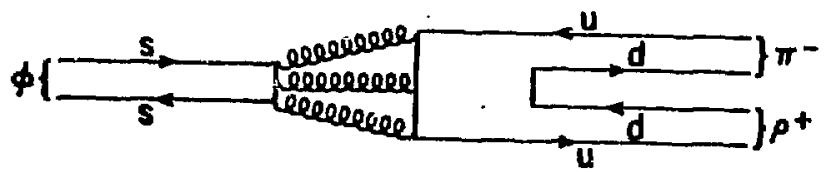

Figure 2b: The quark 21ne diagram for the reaction $+p^{+}-$- which is disjoint (1.e. haixpin) and ozI forbidden.

1. an almost pure $\vec{\theta} \overrightarrow{\mathrm{g}}$ meson oyorem. If you look at Fig. Ic from right to left you have two $\bar{s}$ stater disjoint from the $:-$, $p$ and $n$ part of the diagram which is coniected, and contalns only $u$ and $d$ querks. This to basically no different a disjoint diagram than the single production case (F1g. 2c) where the Ozl suppression is

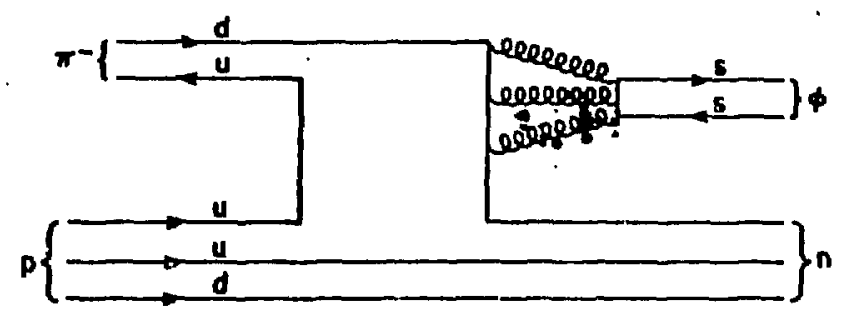

Flgure 2c: The quark 11ne diagram for the reaction $\pi p+$ in which to a digjoinc (i.e. hoirpin) and OzI forbldden. calculated based on experimental results to be just uhat is expected from the decay, a fector 2100.

The following ts an experimental example of another case where a diajoint diagran formed by two particles in the final atate cowposed of new types of quarks and thetr antiquarks leads to 021 auppressior. 25

$\psi(3685) \rightarrow J / 4 \mathrm{n}^{+} \mathrm{x}^{-}(33 \pm 2) \mathrm{x}$, or $\mathrm{J} / 4 \pi^{\circ} \mathrm{n}^{\circ}(17 \pm 2) \mathrm{z}$ The full width of the $\psi(3685)$ is $\mathbf{0} .215$ MeV clearly showling the strong ozI supprcssion corresponding to the fact that the Initial atate contains ci quarks only, whereas the final atare still contains the ec quarks bur the diagran becomes disconnected when $u$ and $d$ quarks and their antiquarke (to form the two plons) are included in the final state.

But you might say what if I introduce two-step processes or other complicated intermediate atates ar processes, other than hard multigluons to $j$ ump the disjointed part of the diagras. The author has discussed this ${ }^{6}$ and shown that the ozI rule 19 pecultar in that you can defart it by two-step processes (P1g. 3) or in QCD language chnng1ng the seture of the mulrtgluon exchange needed in the onestep diagrams to acries of the ordinary 021 allowed givon exchanges.

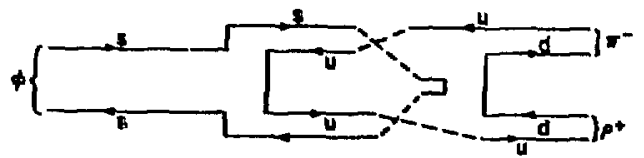

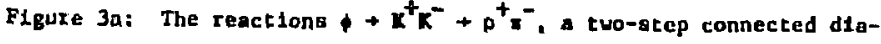
graw uhich appears to be 021 allowed but is not (accordiag to expertment). Proposed cancellations ${ }^{18 b}$ of artificial nature vere proposed to elfminate this problen, but the author belleves the simple Ansatz that they are highly auppressed ts wuch more likely to be consonant with observations and QCD. 


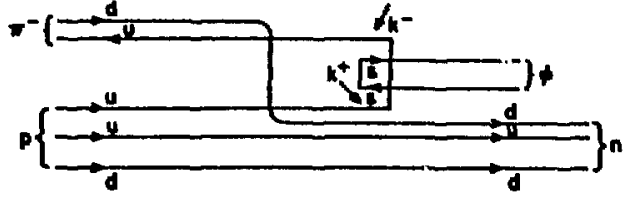

P1gure 3b: The resction $\|^{-} p+K^{+} K^{-} n+\$ n$, a two-Btep connected diagram which appears to be 021 allowed but is not (according to experiment).

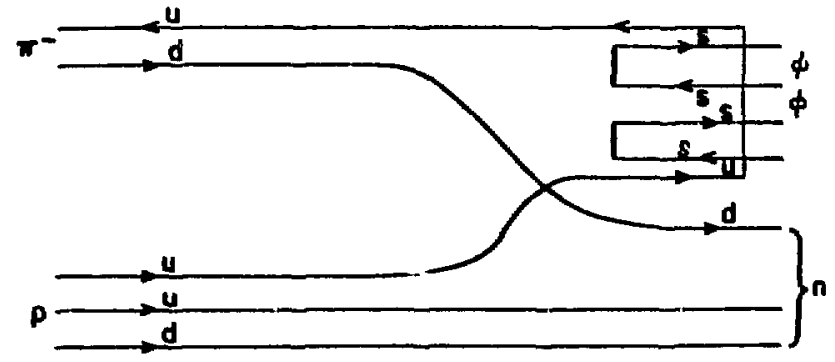

Pigure 3c: The reaction $x^{-} p+\phi k^{+} k^{-} n+\phi \phi n$ via a two-step connected diagras whlch appears to be OZI allowed but 10 not.

In other words, Zweig's dlagrams are, based on all experimental obuervations, to be caken licerally as onc-itep processes and the multigluon exchanges needed to connect disconnected parts of the diagraws are not to be tampered with. Why are these pecullarities observed? I cannot answer that. Nefcher can I answer why color exista, why ronfinement? Why quarks? atc. etc. etc. These are all concepte based on observation.
It 16 certalply consistent with all experimental observations 1n the $\$, J / \psi$ and $T$ aystems that the ozI rule ${ }^{18}$ works very well," and aa I have pointed out if one vante to invent appropriate wulcistop proceases or tamper with the nature of a gluon exheange in the one-step 2we18 diagrams one can defeat the rule." ${ }^{\text {* }}$ Therefors I assume the 021 rule (with the cavests that I have mentioned) as an Input assumption, and of course QCD as an Input assuption in drawlng my concluatoria in th1s paper. If you grant we QCD and O2I as valid agamptions, I vill later conclude that we have discovered one or more glueballa. If you quarrel with essuming QCD, there is absolutely no point in discusalng glueballs. If you quarrel with assuming a2I (as caveated) we vill have to demote our conclusion of glueball diacovery to discovery of strong glueball candidaces, and suggest you explatn wit the assumption of the OzI, rule which has been consistently observed to work be replaced by complicated alternatives. Rewember the name of the phyaics game is almplicity when It works.

THE NEH BNL/CCNY $-p \rightarrow$ p $\rightarrow$ EXPERIMERT

We ut1lized the new Bth. LPS II, the experiwental arrangement of which 18 shown in Fig. 4. The major changes from the kPS I experiments to MPS II experfments was to replace the spark chamber with drift chambers with ten times mare data-gathering rate capability and to improve the (charged particle and $\gamma$ ) veto box around the liquid hydrogen target to obtain an even cleaner neutron Bignal.

* The fact that the 021 rule works well for the single $\phi, J / *$ and $T$ 1s underatandable if there are no glueballs with the right quantum numbers at their masses.

* These restrictions apparently violate crossing and unitarity. 1 consider these peculiarities as another fact of life of quarks, gluons, and color confinevent. 

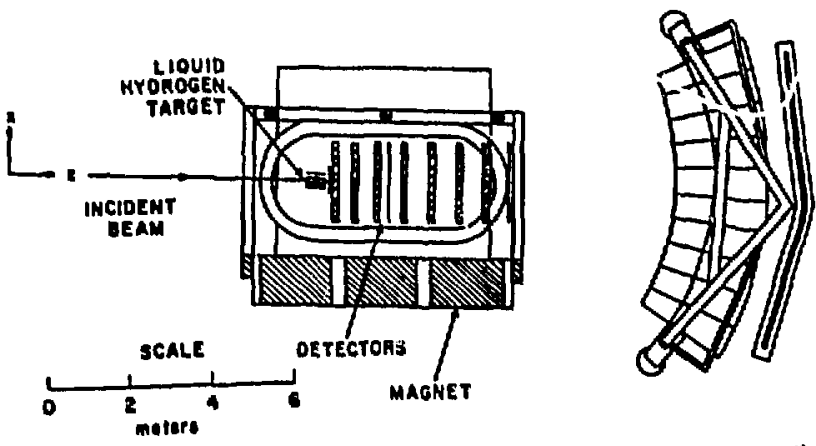

Dowhstagan

F1gure 4: The MPs II and che experimeutal arrangement (see Ref. for further detalls).

Figure 5 18 acatter plot of the wase of one $x^{+} x^{-}$pair versus the was of the second $\mathrm{K}^{+} \mathrm{K}^{-}$pair. Each event has two points on the plot oince there are four possible combinacions. One clearly nozices the two $\$$ bands atanding aut over the 4-kaon background. However, where the two bands craas we flnd a black spot whose peak intenat ty (coriectid for resolution and double counting) is greater then 1,000 tiwer that of the edjolning 4-kaon event 1ncensfty. The band intengity (corrected for resalution) is about - factor of $20 \mathrm{~h}$ gher than the adjaining 4-kan event intensity. Where the two bands crass, che Intenalty (corrected for resolution) is a 50 times greatur than the $\phi\left(x^{+} x^{-}\right)$intenalty. If che 021 guppression were working very 11ttle enhancement vould be ween here. Thus we hav, a patent violation of the 021 euppression. Thil effect was al ready clearly noted by us in $1978 .{ }^{4}$ The speaker has prevloualy ahown that $1 f$ one usen the Loobar nodel, ${ }^{26}$ which 14. well known to work well and has no proviation for OZI suppression

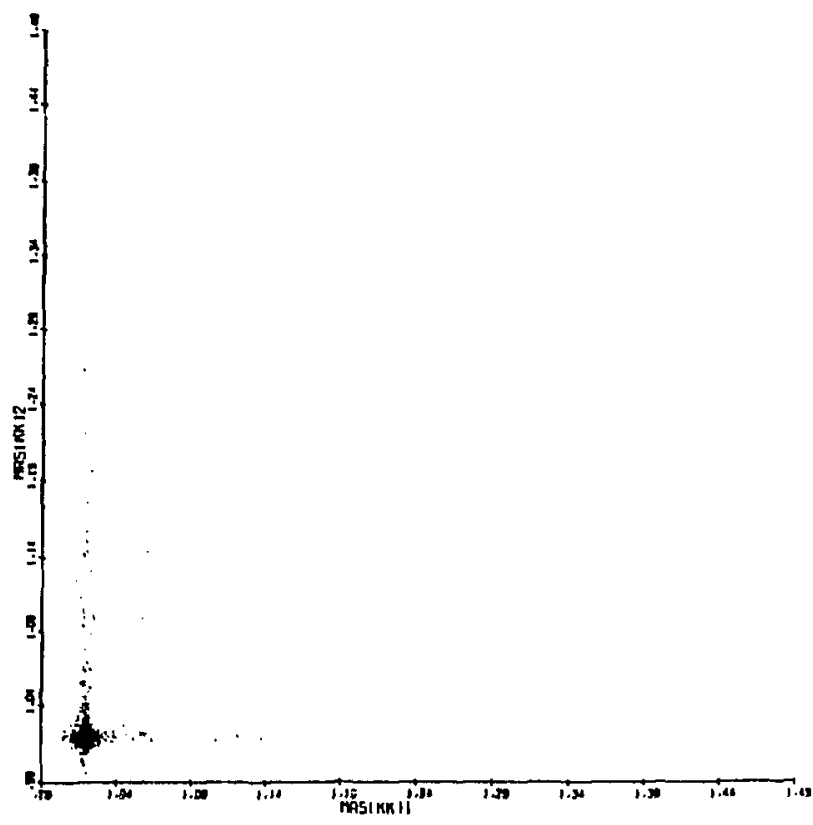

F1gure 5: Scatter plot of $\mathrm{K}^{+} \mathrm{K}^{-}$effective mas, two randouly chosen masa combinations are plotted for each event. Clear bands of $\$(1020)$ are seen with an enorwous enhancement (black opot) where they over lap (1.e. \$).

In 1t, one can quantitacively explain ${ }^{5,6}$ the behavior of th1s scacter plot within a factor of 2. The new greater statistics experimental data are consictent with the carlier experiment in this regard.

Independent evidence of the breakdown of the OZI suppression is B1ven ${ }^{27}$ by a scudy of the reaction $K^{-} p+\phi \$$ or $\$ \phi L^{\circ}$. Th1s is an 021 allowed reaction and yet the crass section obtalned $1 \mathrm{~s}$ 
only a factor a 4 Jarger than the crons section for : $\rightarrow$ th which is an 021 forbidden reaction. We also have kaons in our beaw and have studied this reaction and from preilatinary results obtain the sume factor 24 . One ahould divide the 4 by a factor of 2 since in the $\pi^{-}$case only $a$ is alloved to accompany the $p$, whersas 10 the $x^{-}$case, efther $a A$ or $\Sigma^{\circ}$ is accepted.

Thus within a factor of 2 the two crosa sections are equal, showins little difference between the ozl allowed and forbteden reactione.

Io contrast to this, the ratio 24

$$
\frac{a\left(x^{-} p\right)+11}{O\left(\pi^{-} p\right)+10} * 0
$$

showing the typical OzI suppression of the forbidden to the alloved reaction, and as ts also well known;

$$
\frac{a\left(a^{-} p\right)+u n}{o\left(n^{-} p\right)+p}=100
$$

shous the typlcal ozI auppression $\sim 100$.

Hence we have show in a number of ways that tha large OzI suppression $\approx 100$ expectud in single production is present. whereas that expected in production is broken down to within a factar of 2 of OZI allowed processeg which 18 within the uncertalaties of the comparisons. Thus we can clearly canclinde on a number of grounds that the expected D2I suppression is essentfally entirely absent in the $x+p+\phi$ ozI forbidden process. Figure 6 shous the wasa spectrum of the other $k^{+} k^{-}$pair in one event whenever one $\mathrm{K}^{+} \mathrm{K}^{-}$pair falls in the mass band $(1014.6 \pm 14 \mathrm{MeV})$ and clearly indicntes the huge algnal. Figure 7 ahowe a very clear neutron recoll frow the $\$$ with an estimated contamination of nonneutron events in our data sample $23 x$ which should have a neg11gible effect on our analysis. In the wass region where we did our partial wave analysis, the $\phi \mathrm{K}^{+} \mathrm{K}^{-}$background was small (approximately 10z) and te was tncluded in our analysis.

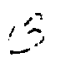

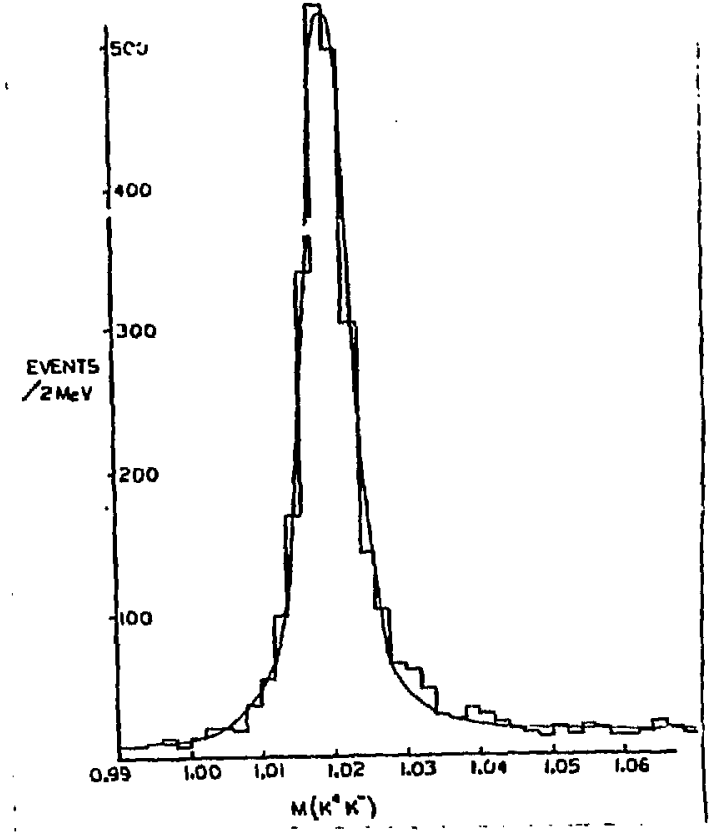

Figure $G$ : The effective mose of each $k^{+} K^{-}$palr for which the other palt was in the mass band.

The histogram in Fig. 8 shows the detected $\$$ effective mass spectrum tor $1203 n$ n +4 with an est Imated background of 130 events frnm $\phi K^{+} K^{-}$( $A, 10 \%$ ) and $\rightarrow 40$ events of non-neutron recoll. The dashed IIne is the Monte Carlo determined acceptance of the apparatus of our portial wave anolysis solucion to be discussed 1ater. However one should note that the result obtained for the acceptance to close to that one would obtain from phase space. Furthermore the results of the partial wave analysis are tnsenstrive to considerable changes in the acceptance. The observed

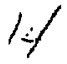




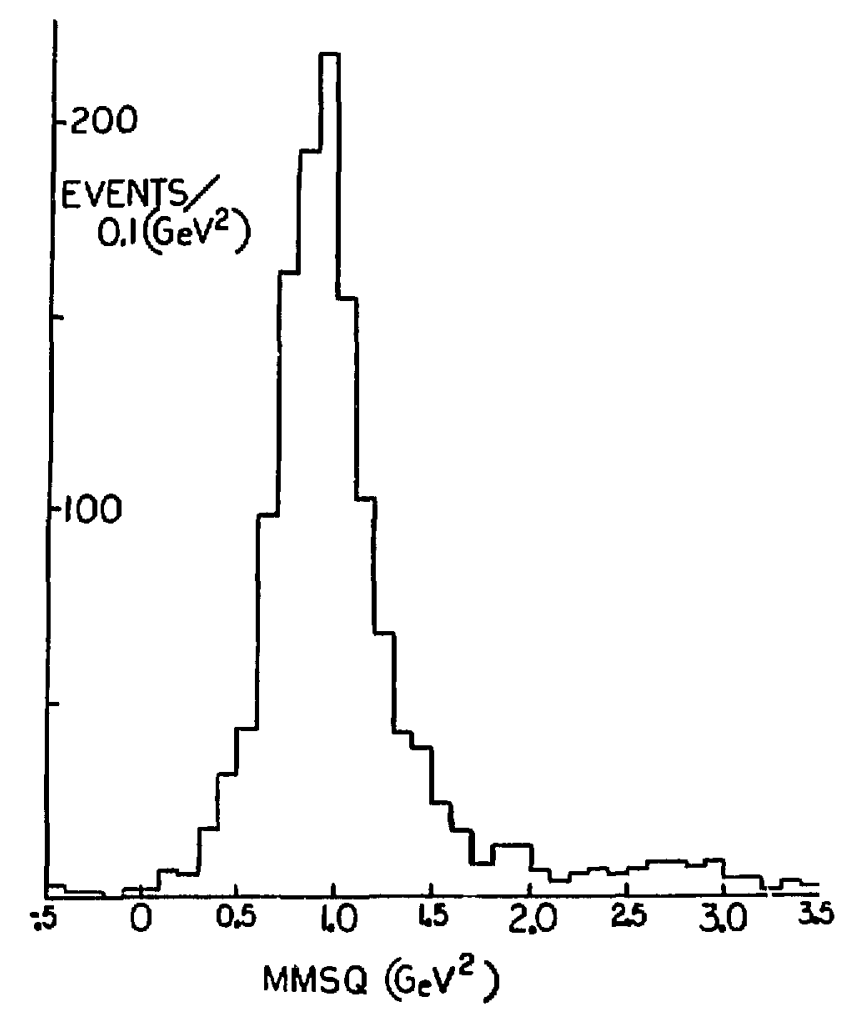

Figure 7: The misolng mass squared for the neutral recolling Byatem from the $\$$.

apectrum is consistent with that of Ref. 3 and ather subsequent low atatigtics ofperiments. ${ }^{19}$ One should note that the $|t:| \leqslant 0.3$

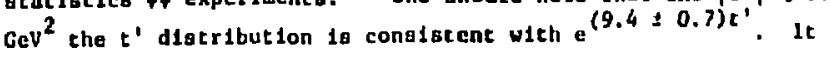

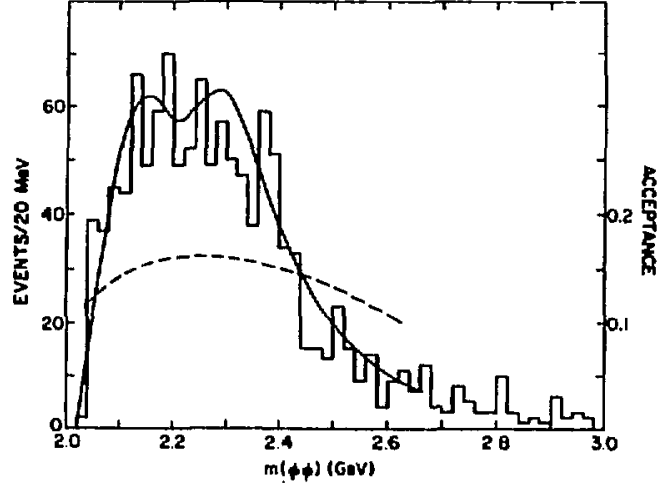

Figure 8: The observed effectlve mass spectrum. The dashed 11 ne $1 \mathrm{~s}$ the Monte Carlo calculated acceptance. The golid line 1s the P.H.A. fit to be discussed later.

should be noted that the $\phi$ mass spectrum frow $K^{-} \rightarrow \phi \phi / \varepsilon^{27}$ is much broader and extends to much higher wasses (see F1g. 9).

THE PARTIAL have ANALYSIS

In order to perform the partial wave analysis (PWA) we used s1x angles to specify all k1nematie and other characteristics of che systeri with each decaying into a $k^{+} K^{-}$palr.

Figure 10 shows the Gotefrled-Jackion frame (which is the rest frame for the $\phi$ system). The usual GJ angles, $B$ (polar) and $Y$ az1muthal, were employed. We then considered the rest frame of each $\$$.

Figure 11 shows the rest frame of $\uparrow_{1}$. In 1 we label the polar angle of the decay of the $k_{1}^{+}$relative to the direction as $\theta_{1}$. and the azimuthal angle of the decaying $k_{1}^{+}$as $a_{1}$. There 19 


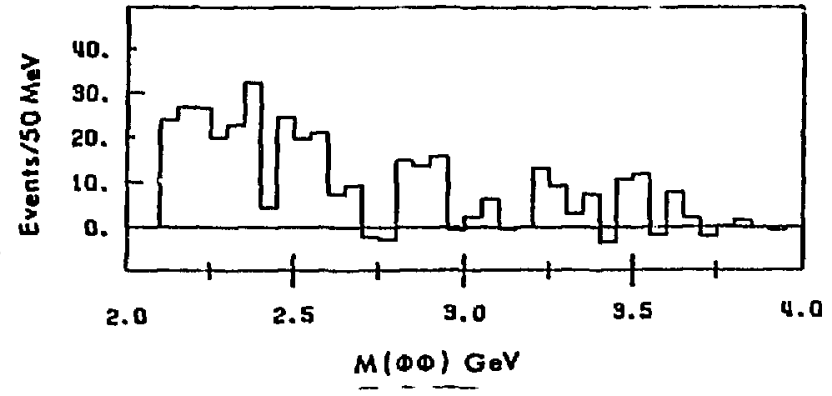

Figure 9: The $\$$ effective mass spectrus for $K^{-} p+\phi N / L$.

2 simflar rest frame (not show) for the second p with corresponding polar angle for $\mathrm{k}_{2}^{+}$of $\mathrm{O}_{2}$ and azimuthal angle $a_{2}$. Since the azimuthal angles a are the same in exther reat frame, $a_{2}$ is shown in the rest frame of $a_{1}$. However, of course, $\theta$ is different in the two rest frames,

Since the decay kaons are spinless, these six angles specify everything for the byatem decaying into kans. These angles and relevant comblnations of them were used in the parkial wave analysis. For the $\phi \phi$ eystem, $I=0$ and $C=+$

The partial waves considered were all waves with $J-0,1,2,3,4$; $L=0,1,2,3 ; S=0,1,2 ;-J \leq M \leq J, P= \pm, \eta= \pm$ where $J$ is the total angular momentum of the system. $L$ is the orbital angular momentum, $M$ is $J_{z}, P$ is the parity and $n$ the exchange naturality of the wave.

Due to the Identity of the two mesons bose statistics requites that $L+S=$ even number, and this was an Imposed requirewent. The above critersa led to a group of 52 independent waves. The maximus 11ks1 thood method was used for the PHA. In order to deterralne the partial waves playing a major role in the $\$ \phi$ system, the events in the masa region 2.3 to $2.3 \mathrm{GeV}$ were fitted with an

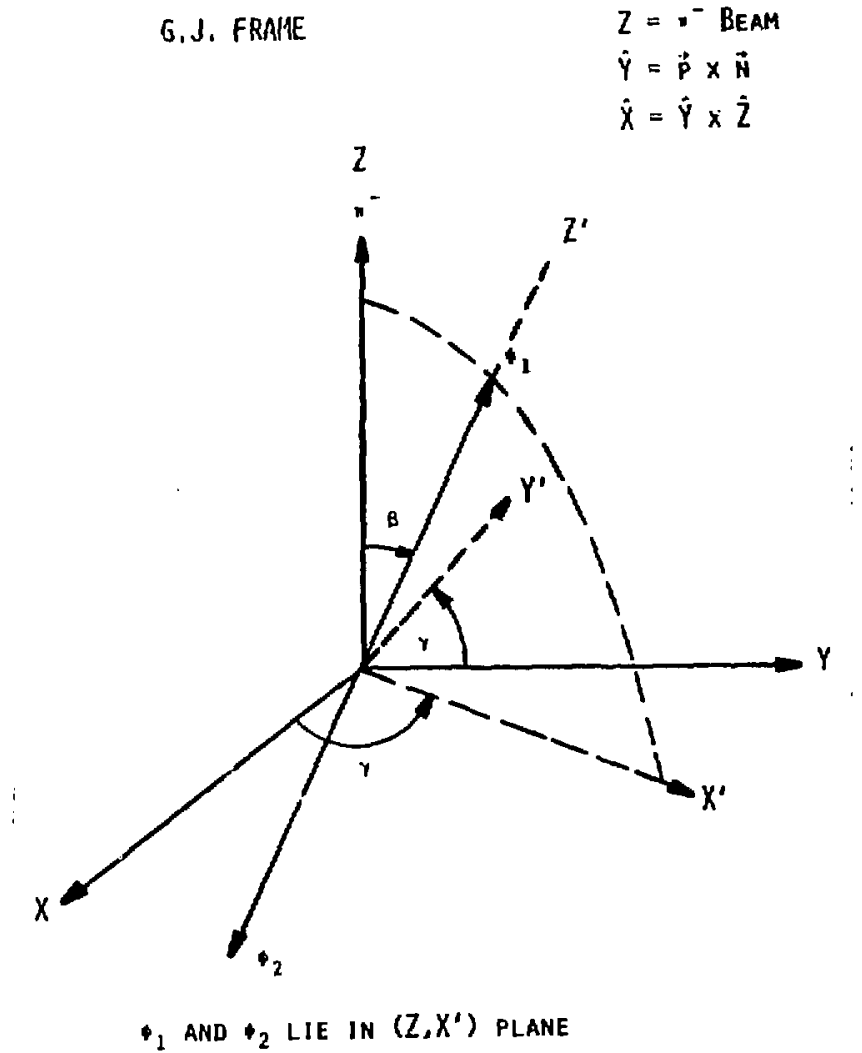

Figure 10: Tho Gottried-Jackson frame with polar angle $\theta$ and azimuthal angle $\gamma$. 


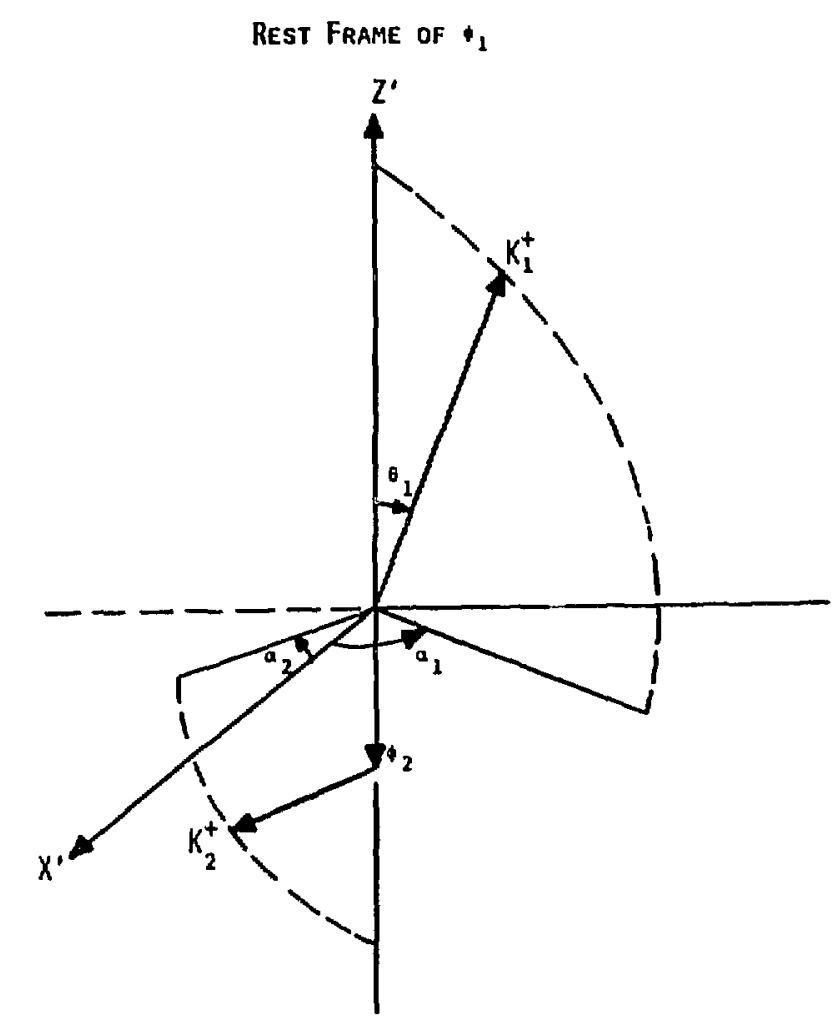

Figure 11: The 4 rest frame with the polar angle $\theta_{1}$ of the decay $\mathrm{K}_{1}^{+}$(relative to direction) and the aztmuthal angle $a_{1}$ of the decay $k_{1}^{+}$.
Incoherent background plus one addittonal parctal wave of spectific $J^{P}$. S, L, $M$ and $n$. cycling through each of the 52 waves described above. The largest, and only gignificart contribution came from $\mathrm{J}^{\mathrm{PC}} \mathrm{SLM}^{\mathrm{n}}=2^{++} 200^{\circ}$. Thls wave was retalned and in order to search for other waves each of the other 51 were added one at a time In turn. The only significant additional contribution came from $J^{P} \operatorname{SLM}^{n}-2^{+} 220^{-}$. These two waves were then retained and each of the ramaining fifty were added one at a time in turn. No algnificant contribution frow any other wave was found. The data vere then divlded up fato flve adjoinlng $100 \mathrm{MeV}$ wide bins starting

from thresnold, so that we could explore the mass dependence of the partial wave structure. The bin size was chosen becsuse about 200 events per bin are neecied to obtain zelfable solutlons.

The background from $q \mathrm{~K}^{+} \mathrm{K}^{-}$events (ft 11z) was estimat ad from on examination of the regiona adjacent to the $\phi \phi$ peak. There was no evidence of any angular structure, so this background was repreaented by a flat distribution in all angles. A maximum likelthood fit to the flup hins using the two $\mathrm{J}^{\mathrm{P}}=2^{+}$waves described gave a very good fit $\tan x^{2} / D . F . \approx 1$ when the stacistics and systematic etrors vere considezed. To ensure that no other combination of two waves would give an equivalent fit, each posafble conbination of two waves, 1.e. $52 \times 51 / 2$ - 1326, were tried in the central bin where the $S$ and $D$ waves found had a algnificant overlap. The clubest one came to a fit wa: Sa aray from the original fit. These $\sim 50$ fitc always involved ths S-wave originally found as one of the two waves. . Hence the originst two-wave fit is clearly selected."

Therefore the wass indepandent solutions (1.e. no paramecerization chosen) for the $\mathrm{S}^{\mathrm{P}} \mathrm{SLM}^{\mathrm{r}_{1}}-2^{+} 200^{-} \mathrm{S}$-wave and the $2^{+} 220^{-}$D-wave are show in Fig. 12. The Jouser half of the figure shows the $|s|^{2}$ * One wighe perhaps expece a anckground of the $L=0, J^{P}=0^{+}$wave at threshold, but this wave cortributes only $10: 5 x$ of the events in the lowest mase bin. Fur: if rmore one should recall backgrounds do not break down 021 supprestion. 


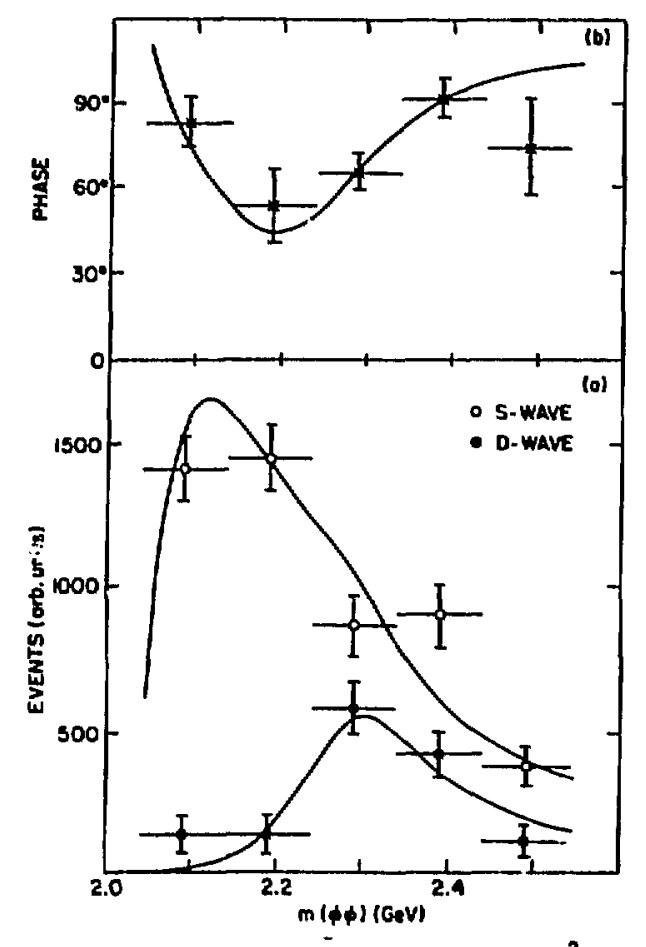

Figure 12: (a) The pointe show the intensity $\left(|s|^{2}\right.$ and $|p|^{2}$ ) and for the best mass-independent two-wave f1t described In the text.

(b) The D-S phase difference (mass-Independent) for the bent two-wave fit described in the text. The curves ahow the resultant best maximum $11 \mathrm{k}=1$ hhood $\mathrm{f} 1 \mathrm{ta}$ for the perameterization of two Interfering BreitHignar resonances. normajized to events as the opan ciscle pointe and the correspondin $|0|^{2}$ anplisudes squared are ahom as the closed points. The $x$ polnts on the top port of the E1sure ahow the D-S phene difference. A natural paraneteriention for these data 10 onc or two Breit-Higne:- A one Brelt-Higner fit us refected by $>100$. primurily because of the phase difference. A tuo Breit-Wigner fit on the other hand wan very good with $x^{2} / p y \approx 1$. The solld line shou this f1t and the quantwa nuabers and parumeters of the two reanances to be discuased jater are shown in Table $I$.

\section{TABLE I}

Quantus numbers $x$ רd parameters of the sreit-Higner resonance fit to the S- and D-tave applitudes (and Fhase difference) of $\mathrm{YH}_{\mathrm{g}}, 22$
$1^{G} \mathrm{JC}^{\mathrm{PC}}$

Hass (GeV)

$r_{\text {tot }}$

Ra:10 of Partiel wIdths

$\frac{B_{T}(2160)}{0^{+} 2^{T}}$
$2.16 \pm 0.05$
$0.31 \pm 0.07$
$r_{D} / r_{S} \neq 0.02$
$\frac{8_{T}(2320)}{t^{+}+t}$

$2.32 \pm 0.04$ $0.22 \pm 0.07$ $r_{s} / r_{D} \approx 0.04$ 1t at f1rst apptars remarkable that we can demongtrate such selectivity (1.e. 2 waves selected out of 52). Houever this results frow the fact that the systed is a very powerful analysis aystem for plcking particular waves. In order to see how thla comes obout let us look at Figs. 13a and 13b there sngular veriables for: numerous allowed (1.e. $\mathrm{L}+\mathrm{s}$ = even) pure waveo up to $\mathrm{J}^{\mathrm{PC}}-4^{4}$ are show. Our date shows a flat distribution in $\gamma, \$ 11 M=0$ waves which are shown have th1s feature. Therefore there 1a no need to plot $\gamma$.

We can notice from these flgures whych shou the behavior of $a_{,} a_{i}^{\prime}-a_{2}^{\prime}, a_{i}^{\prime}+a_{2}^{\prime}, \cos \theta, \cos \theta, \cos \theta_{i}^{\prime}+\cos \theta_{2}^{\prime}, \cos \theta_{i}^{\prime}-\cos \theta_{2}^{\prime}$. that each wave has 1 ts own charasteristic signature in the various variables shown. The primes (1.e. $a_{1}^{\prime}-a_{2}^{0}$ ) were modificatlons to 

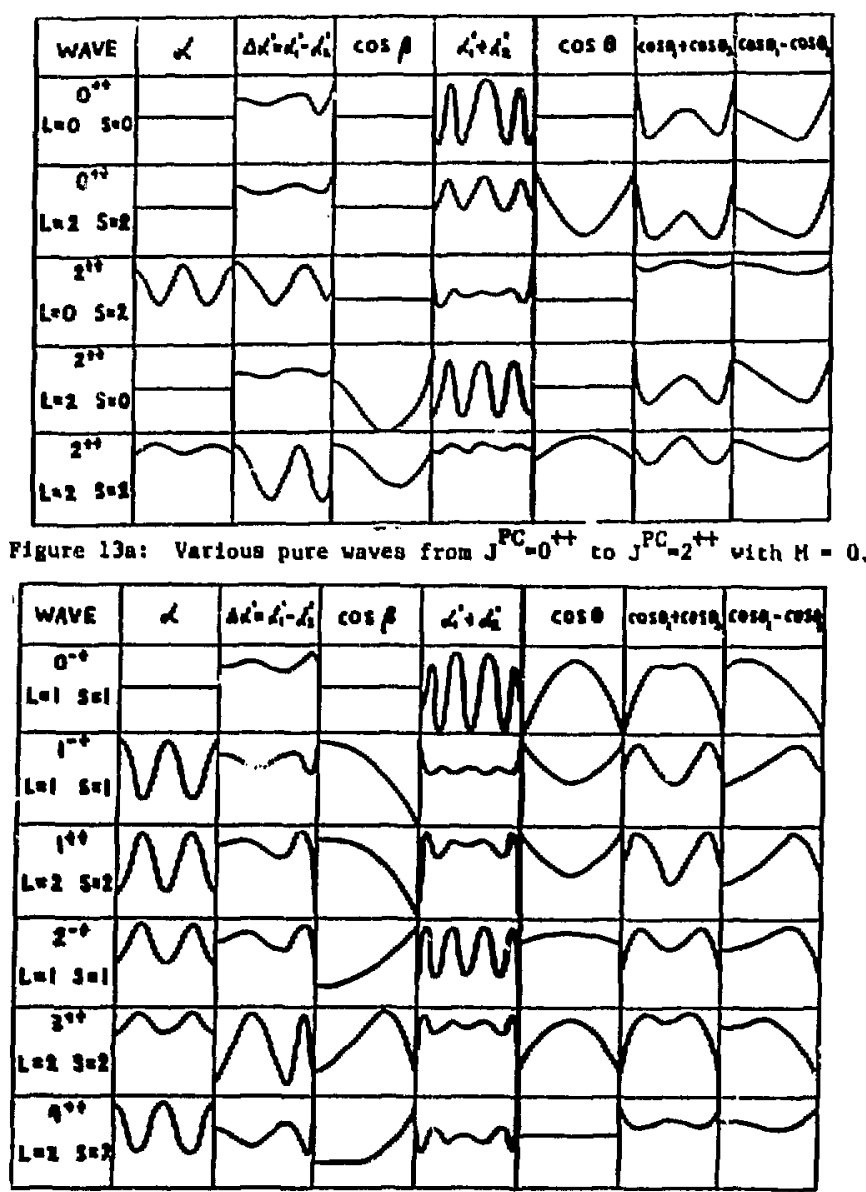

F1gure 13b: Various pure waves from $\mathrm{J}^{\mathrm{PC}_{\mathrm{m}}{ }^{-}}$to $\mathrm{J}^{\mathrm{PC}} \mathrm{4}^{+}$with $\mathrm{H}=0$. the variables for display and comparison purposes so as to equalize the phese opace in each histogram bin (to be shown later). For example

$$
\Delta a^{\prime}=\frac{\left(a_{1}-a_{2}\right)}{\pi} \frac{\left(1-\left|a_{1}-a_{2}\right|\right)}{4 \pi} \text {. }
$$

Slallar equalizations in phase space were wade per bln wherever primes are shown. Due to the inherent symetry, cos $\beta, \Delta a^{\prime}=a_{j}$ $a^{\prime}{ }_{2}$, and $\cos \theta ;-\cos \theta_{2}^{\prime}$ have been folded, the data for $a_{1}$ und $a_{2}$ added, and the data for $\cos _{1}$ and $\cos _{2}$ added. The very characteristic algnature for particular pure uavee in these angular variables give us the great selectivity we have found. For example, notice that the two $\mathrm{J}^{\mathrm{P}}-2^{+}$( $S$ and $D$ ) waves that we have found in the partlal wave analyois (the third and the flfth fros the top in Fig. 13a) have similar very characteriatic large structure in a $a_{2}^{\prime}$ and the S-wave has a characteriatlc atructure in a whereas the D-wave dnes not. Thus $a_{i}^{\prime}-a_{i}$ and $a$ are the mast 1aportant variables in selecting the $\mathrm{J}^{\mathrm{P}}=2^{+}$waved we found in our partial wave analysis.

With this intraduction 1 nov turn to a detalled comparison (In 3 mass bins) of the date and the Mante Carlo generated predictlon for our fit from the partial wave analyals. The Monte Carlo results are acceptance-corrected and are based on over 14,000 evants, wore than an order of magnitude wore sta tstics then the date (for which the actual number of events are snown in the plots). Thus the statistical fluctuations in the Monte Carlo results w1II be umall compared to those in the data. Furthermore we determined that the angular variables and correlatlons werc nat sensitive to the acceptance except in the case of the G.J. angle $B$.

Figuze 14 a ollows a compartion of the data and Monte Carlo for y (the G.J. azdmuthal angle) and the polar ungle $\theta$. The agreement 1o excellent.

Figure lib shows a comparioon of the data and Monte Carlo for coss, where $A$ is the G.J. polar angla. Even though cass 1 s sensttive to the acceptance, we obtain a quite reasonable agr ement. 

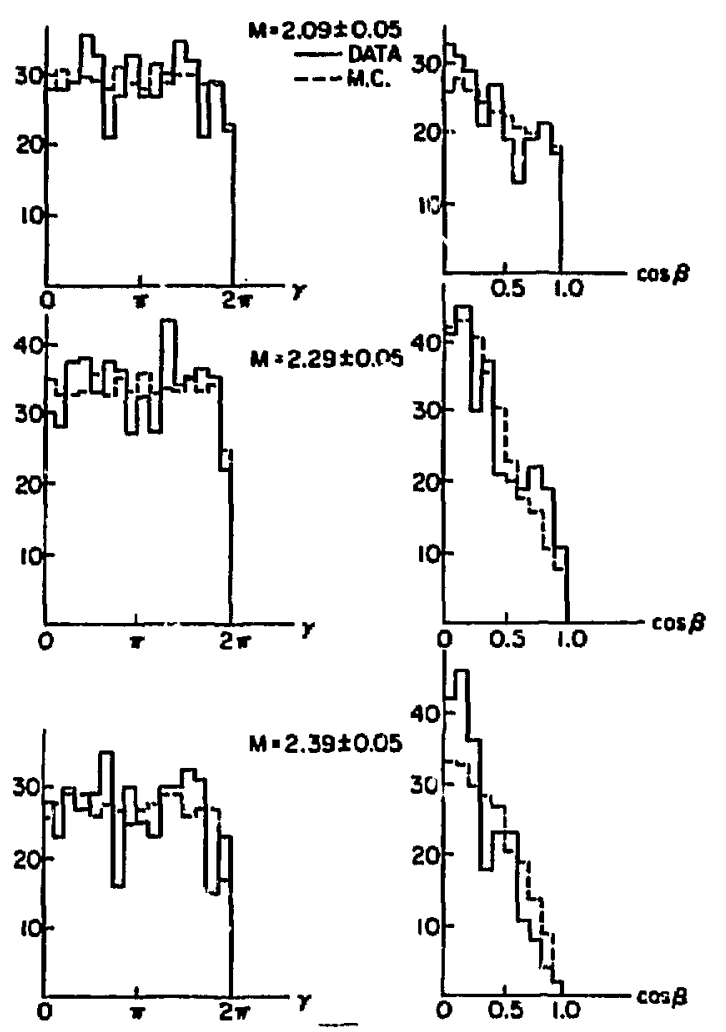

F1gure 14: (a) Comparison of the data and the acceptance-corrected Monte Carlo for the fit in C.J. azinuthal angle $Y$. (b) Comparioon of the data and the acceptance-corrected Monte Carlo for the fit in G.J. polar angle function $\cos \beta$.
Figure 15 show the duta and Monte Carlo predictions of the fit for a and $\Delta a^{\prime}=a_{j}-a_{2}^{\prime}$. The ogreement betvein the dace and the Monte Carlo prediction based on the f1t 1s wont 1mpressive for $\Delta a^{\prime}$ since there are larze factors $z 3$ between praks and valleys.

In the case of a the agreement 18 also quite good. The first bin shows large gtructure, characceriatic of the $S$-uave, as ve have remarked previougly. The next bin shown (third bin) 1s where the D-une 18 very isportant and ahous very 11 trle structure in $a_{1}$, which, as we pointed out prevlously, 10 a fedture of the D-wave. The agreement is good. The nert bin shaus the structure recurniag a the D-wave drops down and again Indicating good agreesent.

F1gure 16 shous the comparison of the data with the Honte carlo for $a_{i}^{\prime}+a_{i}^{\prime}$ and $\cos \theta$. Here again the agreement is generally quite good and there 1a no sizeable structure in these variables.

Figure 17 shows the comperison with the Monte Carlo for $\cos \theta i-\cos \theta_{2}^{\prime}$ and $\cos \theta_{1}^{\prime}+\cos \theta \frac{1}{2}$. Here ogain the agreement 1 s quite good and there to no sizeable structure in these variables.

Thus we have made cent charscteriscic angular correlations for s1x Independent variables and found good agreement - striking at times in $\mathrm{f}^{\prime} \mathrm{a}^{\prime}$ and $a$ for example. The date and Monte Carlu agree in all mass bins in all variables.

The next question is how does our fit compare ulth the observed pouss spectrum? Th1s is shown in Fig. 18 where the solid line in the fit prediction. The agrement here 1t wlso quite good. However, I must remark that In dealing with the of ayatem. 1ts myriad and characteristic anguler distributions and angular correlations are much more important teste of the significance of the $f 1 t$, than the mass spectrus. Thus we can feel quite confident that our two Brcit-Wigner f1ts are in excellent agreement with the data.

* a representa the dats for $a_{1}$ and tho daca for $a_{2}$ added due to symetry. Coso represents the data far $\cos \theta$ and the data for $\cos 0_{2}$, added duc to symetry.

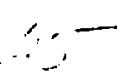



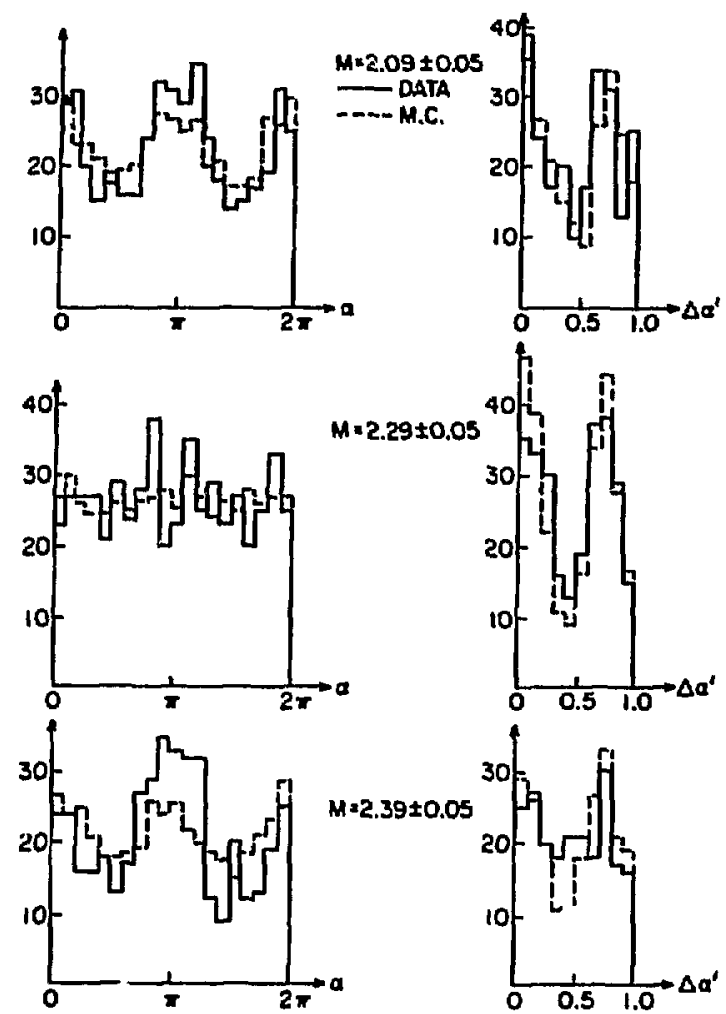

F1gure 15: (a) Compartion of the dato and the acceptunce--ortected Monte Carlo for the azlunchal angle a of the decay $\mathrm{K}^{+}$in che trest frame.

(b) Comparioon of $\Delta a^{\prime}-a_{1}^{\prime}-a_{2}^{\prime}$ with the scceptancecorrected Honce Car1o for the fit.
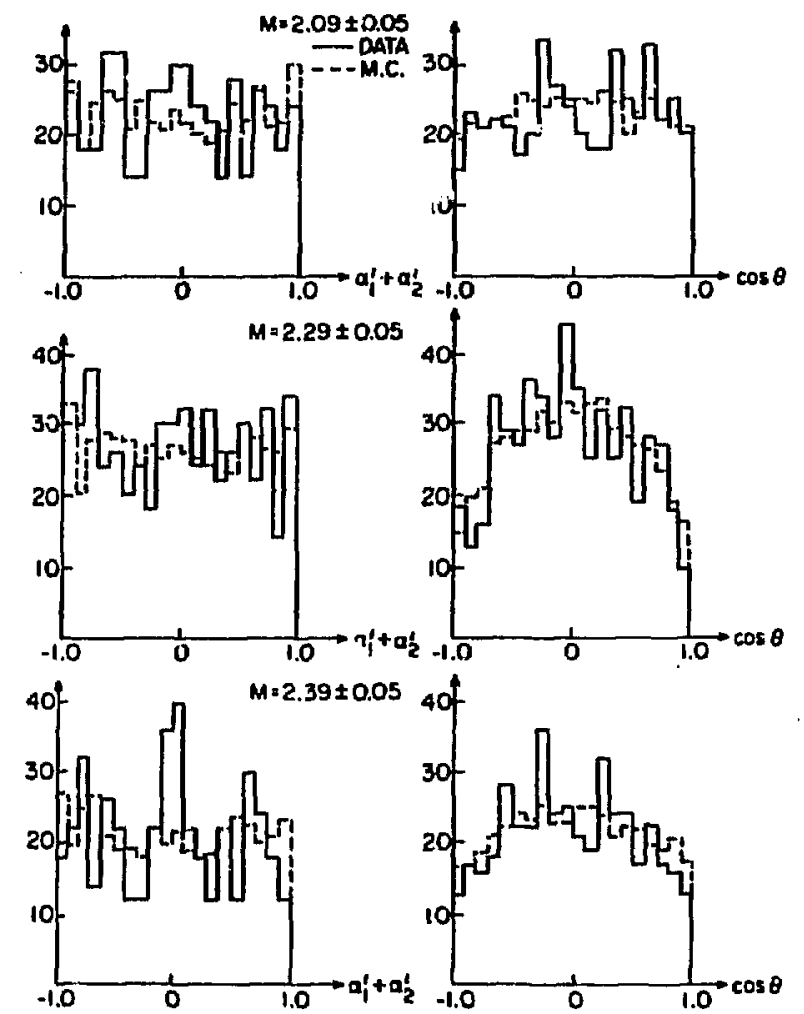

Figure 16: (a) Comparison of the data and the acceptance-corrected Monte Car3o for $a_{i}+a_{2}$.

(b) Comparison of the data and the acceptance-corrected Mante Carlo for $\cos \theta$. 

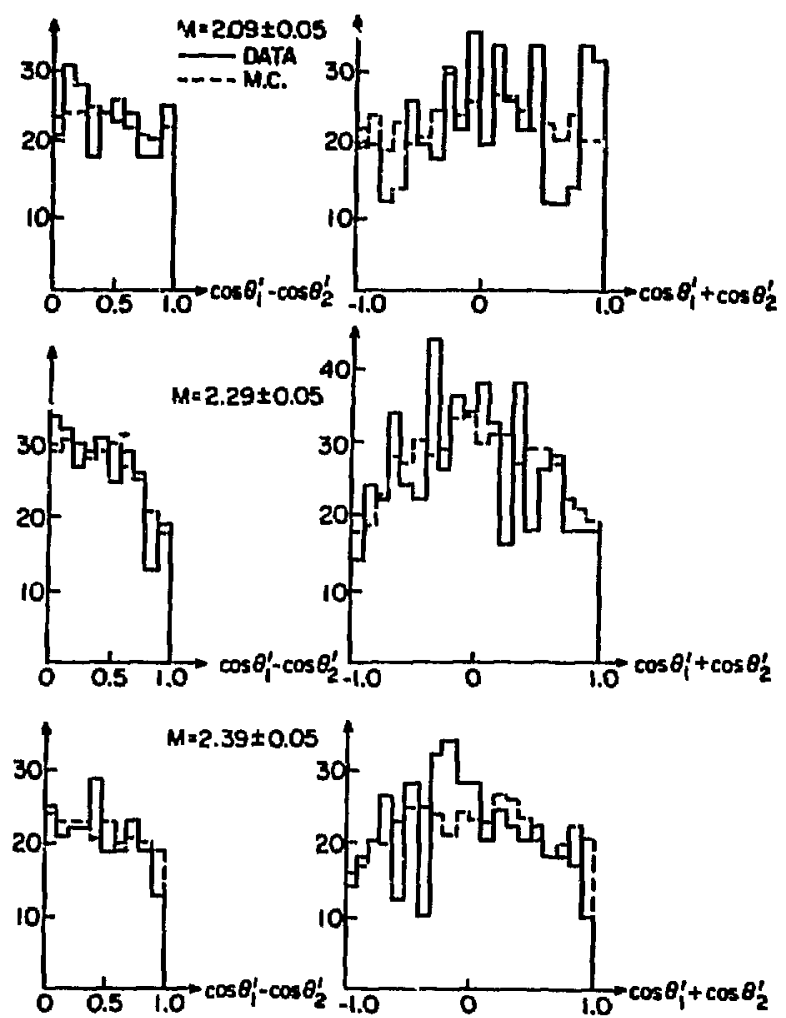

Figure 17: (a) Comparison of the data and the acceptance-corrected Monte $\cos 30$ for $\cos \theta_{1}-\cos \theta_{2}^{\prime}$.

(b) Comparieon of the data and the acceptante-corrected Monte Carlo tor $\cos \theta i+\cos \theta !$.

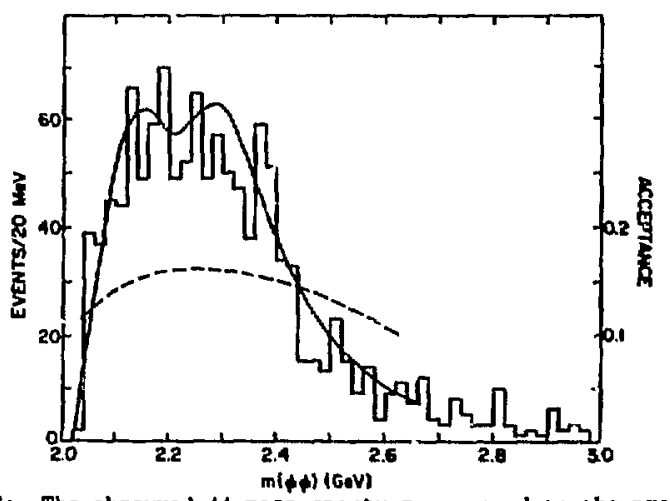

Figure 18: The observed mass spectrum compared to the predicted (solld line curve) mass apectrum from the acceptancecorrected fit. The dashed line is the acceptance.

The mass and full width, partiel width ratios, and all the quantulin numbers for these two Breft-Higner resonances are given In Table 1. They are at the very least strong gluebull candidates due to the breakdom of the OZI Euppression, and the striking selectivity of 2 out of 52 possible waves selected.

In fact if one assumes:

1. The correctness of $Q \mathrm{QCD}$;

2. The universality of the 021 rule (with the necessary caveats) as described previously. Nanely, the necessary one-step requirement which is equivalent to the requirement that there is no change in the nature of a gluon exchange. The above is equivalent to the statament that a dsjoint Zue1s diagiam, due to introduction of a new cype of qā patrs, wust involve is multigluon exchange. This leads to 0zI suppression due to a deakly coupled multigluon exchange. As $I$ have pointed out previously, a glvebald in which the gluons besonate would lead to effectively stronglycoupled stue, and break down the 02I suppression. 
Th1s leaven we ad the only explanation of the 021 suppression breakdown and the observed selectivity the presence of one or two priascy glueball" In the anse region with these quentum numbera. Impurs $q \vec{q}$ intermedince atates, 4 quark states, etc. are ruled out by the above assumptions (sssumption 2).

thy do I say one or two primary elueballs? Because one prizary gluebull could break down the 0zI vuppression and possibly nix with a nearby quark atate with the aame quantum numberg ylelding two acates very rich in resonating glue. Of course both states could come from different primary glueballs * since we expect that there in a glueball apectrum of states - not just a single glueball.

It should be noted that in a number of papers it was concluded that the width of a glueball should be narrower than hadronic resonances typically by a factor $\approx \sqrt{021 \text { suppression factor. }}$. These consideraciona were based on treating the quark-glue, glue-glue coupling as weak, and clearly do not apply if the glue-glue coupling becomes atrong enough to forw a resonnace, in which case we are generally dealing with a very atrongly interacting multigluon resonance.

In fact the glue-glue coupling is effectively stionger than the quark-glue coupling, and therefore, glueballa should be as wide, or wider than, typical hadronic resonances in the mass region.

In Table II ve list ome typical resonance widths from the particle data group tables and widthe for other glueball candidatea. We see that $r \sim(200-300) \pm 100 \mathrm{MeV}$ are reasonable values for glueballa.

MASS AND J $\mathrm{J}^{\text {PC }}$ OF THE GLUEBALLS FROM yARIOUS PHENOMENOLOGICAL APPROACHES

In constituent glueball models ${ }^{12}$ due to confinement, the gluon is considered to have an effective mass $m_{g} \approx 0.75 \mathrm{Gev}{ }^{28}$

* They might also eventually drass theoselves to nome degree with qवं pairs.
TABLE II

Past Resorance Widths for Some Hadronic Resonances from the Particle Daca Group Table 25

\begin{tabular}{|c|c|c|}
\hline \multicolumn{3}{|c|}{$3^{G}\left(J^{p}\right) c^{n}$} \\
\hline $8(1690)$ & $3^{+}\left(3^{-}\right)^{-}$ & $200 \div 20$ \\
\hline$p^{\prime}(1600)$ & ]$^{+}(1)^{-}$ & $302 \pm 100$ \\
\hline$f(1270)$ & $0^{4}\left(2^{\frac{1}{3}}\right)^{+}$ & $179 \pm 20$ \\
\hline Resonance & Other G1 & Candidutes $9,10,15$ \\
\hline SLAC $:(1440)$ & $\left(0^{-}\right)+$ & $55_{-30}^{+20}$ \\
\hline$\theta(1640)$ & $\left(2^{+}\right)+$ & $220^{+100}-70$ \\
\hline $\mathrm{BNL} / \mathrm{CCNY} \mathrm{B}_{\mathrm{B}}(1240)$ & $0^{+}\left(0^{++}\right)$ & $240 \pm 10$ \\
\hline
\end{tabular}

Tlus we wight expect to be in the three-gluon sector. One stould nate that due to the celf-coupling between the gluons and thelx splittings that a gauge invariant description with a definite aumber of gluone 1s not possible. Neverthelens it is physically appealing and reasonable to expect in constit dent gluon nodels that the lowest lying zround state would be mostly composed of 2 gluons and have mase $z 2 \times 0.75 \mathrm{GoV} \neq 1.5 \mathrm{GeV}$. One would expect another ground state in the 38 sector nostly composed of 3 gluons with a mess $3 \times 0.75 \mathrm{GeV}$ ₹? $2.25 \mathrm{GeV}$.

The MIT bas calculations of giuebel1e 29 asume maseless gluone and obtain predictions for quantum numbers and masses of various atate. ${ }^{29}$ The magaes do not $\$ 1 t$ jowe preaent glueball candidates. Hyperf tae energy whifts that depend on $a_{8}$ have been put into the bas calculations to allow such fite. ${ }^{30}$ Adapting these methods, we have derived $m$ for two-gluon atates a a function of $a$. The SLAC (1440) snd $8(1640)$ glueball candidates, and the BNL/CCIY $\mathrm{B}_{\mathrm{s}}(1240)$ glueball candidate, were tsed a Inputs to derive the resulte Bhown in Fig. 19. As you can 8ee, we can obtain $a 3^{\mathrm{PC}}=2^{H+}$ $\varepsilon_{\tau}(2160)$ at about the r1ght wass as an excited state in the 28 


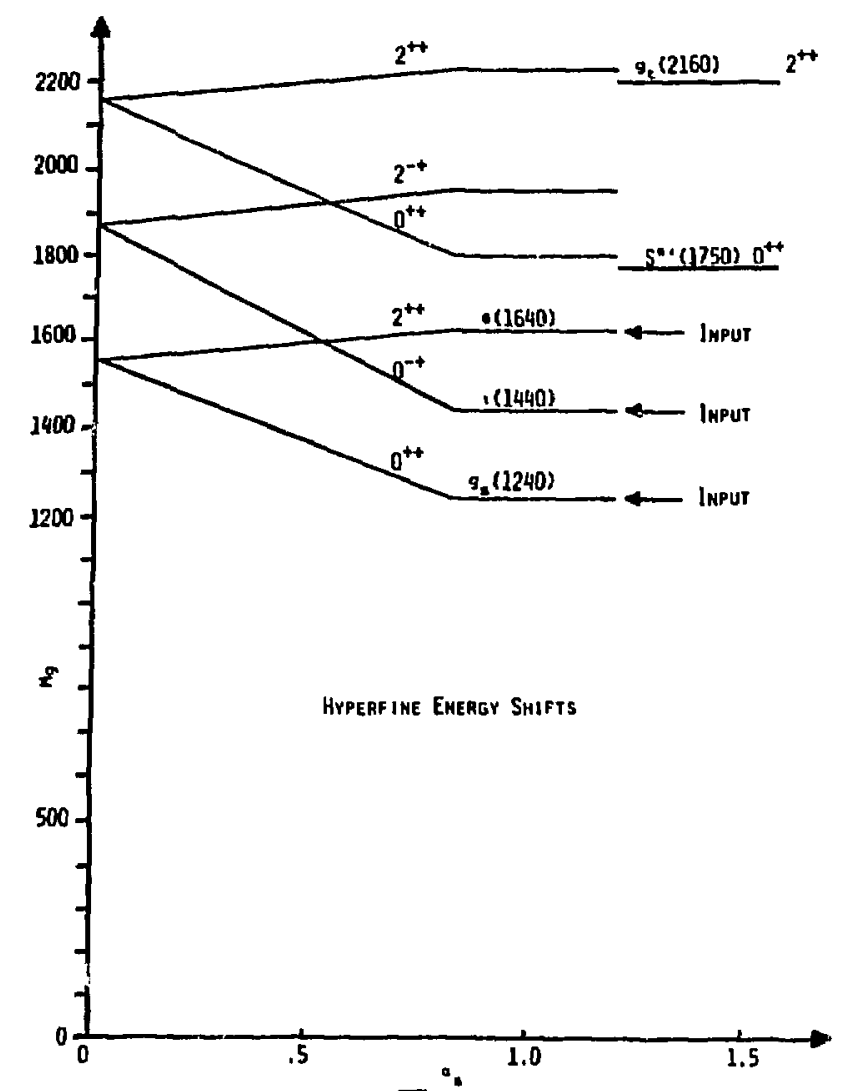

P1gure 19: The predicted aars and quantum numbers of the 28 glueballs from adopting the methods of Ref. 30 . The I(1440), $O(1640)$ and $B_{B}(1240)$ were used as Input to determine the overall uass level, the spacing between the levels, and $a_{g}$ (t11) break in 11nea). sector." However, the massleas assumption for giluong to the bag does not allow $\mathrm{J}^{\mathrm{PC}}$. $2^{\text {+t }}$ for lowlying 3-gluon atates, In contrast to the constitueat gluan model which allowa $a 11 \mathrm{~J}^{\mathrm{PC}}$ for $3 \mathrm{~g}$ states and all $\mathrm{J}^{\mathrm{Pt}}(1, \mathrm{e.}, \mathrm{C}=+$ ) for $2 \mathrm{~g}$ stares.

So far, lattice calculations 31 have concentrated aainly on the gluebull ground atate getting $\mathrm{J}^{\mathrm{PC}}=\mathrm{O}^{++}, \mathrm{M} \sim 0 . \mathrm{0}-1.0 \mathrm{GeV}$. Recently thiey have begun to attack higher ap1n matea. ${ }^{31}$ The work is still prellalnary, but indications are that hipher spin atetes could well show up in our aess region. Thus, In sumary, one finds that the phenosenological models are generally comptible with oux resulca. except for the possiblulty of the HIT bag calculations if we are in the 38 sector.

\section{CONCLUS LONS}

G1ven QCD as an Ansate and 0ZI (with appropriate restrictions) as a second Ansatz, I conclude we have dlacovered efther two blueballs with characteristics described below, or two staces very rlch In resonating give formed frow one primary glueball aixing with a nearby quark state of the sawe quantur numbere, thus forming two states.

The quantum numbers and characterlstics of these states are:

\begin{tabular}{|c|c|c|c|c|}
\hline & ]$^{G}$ & $\mathrm{~J}^{\mathrm{PC}}$ & Hass (MeV) & $\Gamma(\mathrm{HeV})$ \\
\hline $\mathrm{B}_{\mathrm{T}}(2160)$ & $0^{+}$ & $2^{i+}$ & $2160 \pm 50$ & $310 \pm 70$ \\
\hline$\varepsilon_{T}(2320)$ & $0^{+}$ & $2^{+4}$ & $2320 \pm 40$ & $220 \pm 70$ \\
\hline
\end{tabular}

\footnotetext{
* However, one ahould be aware that perturbative treatments are
} not jubliflable at high values of $a_{0}$. 
1. C.N. Yang and R.L. M111e, Phys. Kev. 96, 191 (1954).

2. a) Britzech and HLnkousk1, Huovo C1mento 30A, 393 (1975).

b) R.P. Freund and Y. Nambu, Phye. Rev. Lett. 34, 1645 (1975).

c) R. Jaffe and K. Johnson, Phys. Lett. 608, 201 (1976).

d) Kogut, Sinclalix and Susskind, Nucl. Phys. B114, 199 (1975).

e) D. Robson, Kucl. Phya. B130, 328 (1977).

f) J. Bjorken, SLAc Pub. 2372.

3. A. Etk1n, J.J. Folty, J.B. Goldman, W.A. Love, T.W. Morris, S. Ozak1, E.D. Platner, A.C. Saulya, C.D. Wheeler, E.H. Willen, S.J. Lindenbaum, H.A. Kramer, U. Mall1k, Phys, Rev. Lett. 40. 422 (1978).

4. A. Etkin, K.J. Foley, J.H. Goldmen, H.A. Leve, T.H. Mortis, S. Ozak1, E.D. Platner, A.C. Saulys, C.D. Wheeler, B.H. Willen, S.J. LIndenbaum, M.A. Kraner and U. Mall1k, Phys. Rev. Lett. 41. 784 (1978).

5. S.J. LIndenbaum, Hadroalc Physice of $q \bar{q}$ Light Quark Mesons, Quark Moleculen and Glueballu, Lecture presented at XVIII Course: The High Energy Limit, 31 July - 11 August 1980, The International School of Subnuclear Physica, Erice (to be published in proceedinge); Also 8ML. 28498, Occober 1980.

6. S.J. LIndenbaum, Il Nuovo Cimento, 65A, 222 (1981).

7. P. Fishbane, Glueballa, a Little Review. Talk preseuted at the 1981 ORBIS Sclentiae, Pt. Lauderdale, Florida (to be published)

B. D.L. Scharre, Glueballe, A Status Report, ORBIS Scientiee 1982 , Mlami, Forida (to be publ1shed), and SLAC Repore 2880 (1982).

9. D. Antreanyan, Y.F. Gu, J. Irion, W. Kollman, H. Richardaon,

X. Strauch, X. Wacker, A. Weingtein, D.A. Schwan, T. Burnett, H. Cavalli-Sforza, D. Coyne, L. Netran, H.P. Sadrozinak1, D. Gelphmen, K. Kofatadter, R. Horisierger, L. Kirkbride, H. Kolanogk1, K. Konigeman, R. Lee, A. Liberman, J. O'Re11ly, A. Osterheld, B. Pollock, J. Tompkins, E.D. Bloom, F. Bulos,
REFERENCES (conL inued)

Ref. 9 (continued)

R. Chestnut, J. Galser, G. Codfrey, C. KLesilng, W. Lockman,

M. ureglla and D.L. Scharre, Phys. Rev. Lett. 49, 259 (1982).

20. a) M. Chanowlle, Phys. Rev. Letr. 46, 981 (1981).

b) C.E. Caclson, Toyne, P.M. Flshbane, F. Gross and S. Meshkav, Ptyyg. Lett. 988, 110 (1981).

11. J.F. Donoghue, K. Johnson and B. L, Phys. Lett. 998, 416 (1981).

12. a) C. Carlaun, J. Coyne, P. Elshbane, F. Grose, S. Meshkov, Phys. Rev. D23, 2765 (1981).

b) J. Coyne, P. Flohbane and S. Meahkov, Phys. Lett. 91B, 259 (1980); C. Curlson, J. Coyne, P. Fishbane, F. Gross and S. Heshkav, Phyn. LeLt. 998, 353 (1981).

13. S.J. Lindenberm, Proc. S1xteenth Rencontre De Borlond, "Key Flavours and Hadron Spectroscopy." Yol, II, P8. 187, Ed., J. Trap Thanh Ven (Editiona Frontieres, France, 1981); H.J. Schnitzer, 2bid, pg. 648; K.R. Schulert, tbid. Pg. 635.

14. S.J. Lindenbalm, "Evidence for Glueba11s", Proc. 1981 EP Int. Conf. on High Energy Phys1ca, July 9-15, 1981 (Calouste Gubenkian Foundation, Av. Berne, Lisban, Portugal) (to be publlohed): P.E. Cloge, "Glueballa, Jemuphrodltes and QCD Probless for Baryon Sfuckrescopy", tbid.

15. A. Etkin, K.J. Poley, R.S. Lougacre, W.A. Love, T.W. Morris, S. Ozak1, E.D. Platner, Y.A. Polychronakos, A.C. Saulys, Y. Teramoto, C.D. Wheeier, E.H. WIllen, K.H. Lal, S.J. Lindunbaum, M.A. Krawer, U. Mallik, M.A. Mann, R. Merenyl, J. Marraffino, C.E. Roos, M.S. Hebater, Phys. Rev. D2S, 2446 (1982).

16. E. Bloum, talk presented at the XXI Int. Conf, on High Energy Physics, Parle, France, July 26-31, 1982 (to be published) J. Donoghue, Ibld. 
17. a) J.F. Donoghue, Experimental Meson Spectroncopy - 1980, S1xth Int. Conf., Drookhaven Mational Laboratory. April 25-26, 1980, Eda. S.U. Chung and S.J. LIndenbaue, AIP Conf. Prac. 167, Particles and Fielda Subseries 121, Pr. 1040.

b) G. Bhanot, Phya. Lect. 101 B, 95 (1981).

c) G. Bhanat and C. Rebbl, Nuc. Phya. B180, 469 (1981).

a) H. Hauber and G. Par1E1, Phys. Rev. Lett. 47, 1792 (1981).

18. a) S. Okuba, Phyn. Lett. 5, 165 (1963): G. Zue1, CERY Report TH 401 and 412 (1964); J. I1xuba, Prog. Theor. Phym. Supp1. 37-38, 21 (1966); J. I1zuba, K, Okuda and 0 . Shito, Prog. Theor. Phys. 35, 1061 (1966); S. Okubo, "A Survey of the Quark LIne Rula," Univ. Rocheater Report UR 641 (1977).

b) S. Okubo, Phyn. Rev. D 16, 2336 (1977).

c) T. Applequist, K. Kane and M. Barnett, Ann. Rev. Huel. Sc1. 28, 387 (1978).

d) I.J. Muzintch and F.E. Pa1ge, Phya. Mev. D 21, 1151 (1980). e) S.s. Lindenbauw, "Quark Line D1agrans, Rules, and Sone Recent Data", BNL 50812 (December 1977).

19. T.A. Armatrong et el., Nucl. Phys. B 196, 176 (1982); C. Daum et al.. Phys. Letca. 104B, 246 (1981). The narrow enhancement in + palrs produced from be as reported in the latter paper 1s not confirwed by higher atatistica resulta reported by $C$. Daum et al., and by B.R. French et al. at the XXI Int. Conf. on H1gh Energy Physica, Par1s, France, July 26-31, 1982 (to be publ1shed).

20. S. Elseman, A. EtkIn, K.J. Foley, R.S. Longacre, W.A. Love, T.H. Morr1e, S. Ozak1, E.D. Platner, V.A. Polycluronskos, A.C. Saulys, C.D. Wheeler, S.J, LIndenbaum, H.A. Kramer, Y. Teramoto. "The HPS II Drift Chamber Syatem", paper submitced to the IEEE 1982 Huclear Science Symposile, October 20-22. 1982, Hashington D.C. (to be published 1n IEEE Trane. on Nuc1. Se1.).
21. S.J. LIndenbaum, C. Chan, A. Etkin, K.J, Foley, M.A. Krawer, R.S. Longacre, W.A. Lave, T.W. Horrin, E.D. Platner, Y.A. Polychronakos, A.C. Saulya, X. Terawoto, C.D. theelez,

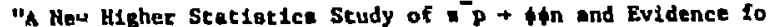
Glucballa". Paper presented at the XXI Int. Conf. on High Energy yhyolcs, Paris, France, July 26-31, 1982 (to be pub11:nhed).

22. H. Fritzch and H. Gell-Mann, XVI Int. Conf. on High Energy Physica, Chicaba-latavie, 1972, Vol. 2, p. 135; H. Friczch, H. Gell-kann and H. Leutwyler, Phys. Lect. 478, 365 (1973); S. WaInberg, Phys. Rev. Lett. 31,494 (1973); S. We1nberg. Phys. Rev, DQ, 4482 (1973); D.J. Grosn and F. Hilczek, 1bid. 3633 (1973).

23. D. Cohen et a1., Phyw, Rev. Lett. 38, 269 (1977).

24. D.S. Ayrea et 11., Phyo. Rev. Lett. 32, 1463 (1974).

25. Particle Date Group Tables, Phyn. Letts. 111B, 12 (1982).

26. S.J. Lindenbaum and R.H. Sternheleer, Phyg. Rev. 105, 1874 (1957); 106, 1107 (1957); 109, 1723 (195E); 123, 333 (1961).

27. T. Armbtrong et a1.. CERK EP/82-103 (1982).

28. C. Parisi and R. Petronz10, Phys. Lete. 94B, 51 (1980).

29 J.F. Donoghue, K. Johnson and BInE An L1, CTP 1891 UN HEP-139 Decober 1980.

30. T. Barnes, 7.E. Close and S. Monoghan, Phys. Lett. 1JOB, 259 (1982).

31. C. Rebb1, talk prebented at the XXI Int. Conf. on High Energy Phynics, Paris, France, July 26-31, 1982 (to be published). 